\title{
Tempo para (re)pensar o aprender em Ciências
}

\section{Time to (re)think about learning in Science}

\author{
Miguel Fonseca*, Tiago Ribeiro**, Elisabete Ferreira** \\ * Universidade do Minho, ** Universidade do Porto
}

\begin{abstract}
Resumo
Neste trabalho, apresentamos alguns contributos para discutir as mediações do aprender e ensinar Ciências através das experiências, narrativas e saberes de estudantes e da sua reflexão sobre o(s) tempo(s) de aprender. Neste sentido, mobilizamos algumas investigações em curso que envolvem o diálogo, a participação e a colaboração de estudantes na sua relação com os sentidos de aprender Ciências no contexto escolar, partindo do (re)conhecimento da possibilidade de construir outros modos e tempos de aprender e ensinar Ciências. Nesta investigação, os estudantes relacionam-se no processo como sujeitos cooperantes, num imaginário de invenção e pertinência científica, questionando os espaços e tempos "objetificantes" da relação educativa.

Palavras chave: Aprendizagem, Autonomia, Ciências e Educação.
\end{abstract}

\begin{abstract}
In this work, we present some contributions to discuss the mediations of learning and teaching Science through the experiences, narratives and knowledge of students and their reflection on the time(s) to learn. In this sense, we mobilize some ongoing research that involves the dialogue, participation and collaboration of students in their relationship with the senses of learning Science in the school context, starting from the knowledge of possibility to construct other ways and times of learning and teaching Sciences. In this research, students are related to the process as cooperating subjects, in an imaginary of invention and scientific pertinence, questioning the "objectifying" spaces and times of the educational relation. Keywords: Learning, Autonomy, Sciences, Education.
\end{abstract}

A Educação habitou, e habita, num espaço e tempo de crescidas incertezas e de muitas perplexidades. Afirma-se a necessidade de mudança, sem conseguirmos definir-lhe uma orientação. Toda e qualquer mudança em Educação tem de ser pensada e estudada criticamente. Pensar criticamente em relação à Escola e seus atores é diminuir a possibilidade de erro, num espaço e tempo de construção de carácter e de seres humanos. Muitos são, assim, os desafios que se colocam à Escola e aos intervenientes no século XXI. A Escola, enquanto espelho da sociedade, está em constante evolução, sendo que as exigências colocadas são cada vez mais intensas e complexas.

Com propósito de contribuir para a discussão destas questões surge, assim, esta investigação. Neste estudo pretende-se perceber, com os jovens alunos, novas e outras formas de aprender e ensinar Ciências, diminuindo o hiato entre os discentes e estas últimas.

$\mathrm{O}$ Ensino das Ciências deve proporcionar a transformação do conhecimento implícito em explícito, sem nunca o subestimar ou desvalorizar. A trajetória do(a) aluno(a), ao longo de um campo concetual científico, é sinuosa, extensa, árdua e demorada (Moreira, 2002). É propósito do(a) professor(a) ser o esteio, e em entreajuda desafiar o/a estudante para que este se desenvolva como ser humano, a todos os níveis, mas de forma cuidada e preparada. Para tal, o(a) professor(a) deve estar atento ao desenvolvimento cognitivo, atitudinal e pessoal dos seus estudantes, às suas continuidades e ruturas, às suas representações simbólicas e análise dos erros e dos insucessos (Vergnaud, 2000), definindo quais as melhores estratégias e abordagens a fazer. De certo modo implica perguntar: Por que não escutar os jovens alunos, sujeitos principais do ato educativo, sobre o que eles pensam e dizem sobre o seu próprio sucesso ou insucesso no estudo das disciplinas mais ligadas às Ciências? (Ferreira, Fonseca \& Teixeira, 2015).

No início do século XXI, os professores, surgiram como elementos necessários à promoção das aprendizagens e à construção de processos de inclusão, de forma a que respondessem aos desafios da diversidade ao desenvolvimento de métodos adequados de utilização das novas tecnologias (Nóvoa \& Bandeira, 2005).

Atualmente, as novas metodologias de ensino-aprendizagem apontam no sentido do ensino orientado para a investigação (Inquiry Based Teaching). $\mathrm{O}$ ensino orientado para a investigação intenta aumentar espaço e tempo para o questionamento, o planeamento, a recolha de evidências e explicações e a sua comunicação no contexto de sala de aula, aumentando a participação e autonomia dos estudantes na construção do saber. Para tal, recorre-se a processos de investigação e conhecimentos científicos, fomentando nos alunos o desenvolvimento de uma correta e acurada conceção de Ciência (Baptista, 2010), aumentado, assim, a sua literacia científica nos três seus domínios principais: saber Ciência, saber fazer Ciência e compreender a natureza da Ciência (Vasconcelos \& Almeida, 2012). A inclusão deste tipo de ensino na sala de aula requer que os professores mudem o seu papel, alterando a dinâmica 
das aulas e a tomada de decisões, correndo riscos de forma a enfrentarem as suas dificuldades e dilemas (Baptista, 2010). Assim, faz todo o sentido que o(a) professor(a) seja, também, um(a) investigador(a).

Importa, pois, (re)pensar, neste novo tempo global e permanentemente relacional, a posição do(a) professor(a), não como o único sujeito responsável pelo ensino dos seus alunos, subordinado exclusivamente ao programa e ao tempo de ensino proposto pela tutela. Deve-se, sim, promover, o mais possível, o seu envolvimento com a comunidade educativa em que se encontra, para um ensino cada vez mais próximo do(s) aluno(s) como resultado de um trabalho de investigação onde a partilha de experiências e saberes diversos resultem numa aprendizagem cooperada e cientificamente rigorosa. Pretende-se, também, através deste trabalho relançar a questão, sempre atual, que o saber raramente é dissociado da pessoa que o encarna e sabemos bem que um(a) bom(a) professor(a) pode tornar prazerosos até mesmo saberes ingratos (Perrenoud, 2001). Assume-se, pois, no âmbito deste trabalho, a abertura e disponibilidade dos professores, para um tempo que viemos a denominar de suplemento pedagógico (Fonseca, Cortizo \& Ferreira, 2016), durante o qual os alunos, jovens investigadores, acompanhados pelos demais elementos da equipa de investigação, partilharam tempos de construção de desafios e procuraram respostas aos problemas por eles identificados. Durante a dinâmica do processo desenvolveram competências para a aplicação dos conhecimentos e a articulação dos saberes numa equipa transversal de cooperação solidária. $\mathrm{O}$ envolvimento registado no processo assemelha-se à partilha de um outro tempo, proposto por Matos (2017), - tempo da relação - e não simplesmente o da linearidade.

A partir da escuta, das dinâmicas e da observação dos estudantes participantes das investigações, torna-se possível perceber o quanto é desafiador para estes jovens compreender, por exemplo, a questão de "não aprender Ciências". As dificuldades assinaladas pelos jovens incluem a falta de bases científicas, a relação com o(a) professor(a) da disciplina e, principalmente, o modo como os conteúdos são trabalhados na Escola, levando que para alguns seja, como dizem, "uma verdadeira seca" ou uma "perda de tempo". De uma maneira geral, percebe-se, através das narrativas presentes nos discursos dos jovens, uma certa relutância no seguimento dos estudos na área científica. Esta "crise da educação científica" manifesta-se na sala de aula com o ensino de uma Ciência desarticulada dos conhecimentos práticos que, por vezes, traduz-se numa aprendizagem descontextualizada e errónea.

\section{Metodologia}

Esta investigação assume um caracter misto (qualitativo e quantitativo), de acordo com uma triangulação metodológica segundo modelo QUAN-QUAL (Gay, Mills \& Airasian, 2011). Os dados obtidos resultam do emprego de vários métodos de recolha de dados como questionários de resposta semiaberta e/ou fechada e entrevistas semiestruturadas e ou de discussões de grupo focalizadas. Esta investigação classifica-se, quanto ao propósito, como aplicada num desenvolvimento de abordagem aproximada à investigação-ação (Gay et al., 2011). Especificamente este estudo resulta da sinergia de duas fases de recolha de dados distintas, quer temporal quer espacialmente. A primeira fase de recolha de dados decorreu de setembro de 2015 a fevereiro de 2016, durante a implementação exploratória do projeto de investigação e intervenção 100CECCA: Conhecer, Estudar e Cooperar em Ciências para Aprender (Fonseca, M., Cortizo, T., \& Ferreira, E., 2016; Martins, J. et al., 2017). Esta amostra de conveniência incluiu alunos de uma escola da região norte do país do $9^{\circ}$ ano de escolaridade, com o propósito de compreender, conjuntamente, novas e outras formas de aprender e ensinar Ciências, em particular Matemática e Físico-Química.

Quanto ao método de investigação, este estudo resulta de uma interação e hibridez metodológica que coloca em diálogo abordagens qualitativas e quantitativas num desenvolvimento pautado pela dinâmica da investigação-ação. Neste âmbito realizaram-se grupos de trabalho de resolução de desafios, questões e curiosidades em grupos de discussão focalizada e em torno da problemática da aprendizagem e ensino de ciências. Do ponto de vista qualitativo, realizaram-se então, dois grupos de discussões focais com uma amostra aproximada de 15 alunos $(n=15)$, e que foram gravados e transcritos para posterior análise. De salientar ainda, no domínio do trabalho qualitativo, os desafios propostos, versavam temas que não estavam diretamente relacionados com os conteúdos programáticos dados às disciplinas de Matemática e de Físico-Química durante as suas aulas e eram realizados e resolvidos em grupos de 3 a 4 alunos, seguidos da exposição a todo o grupo de trabalho os resultados obtidos. Desta forma partilhada, todas as resoluções dos grupos eram conhecidas por todos num tempo que permitia a discussão aberta entre todos com vista a uma síntese crítica do trabalho realizado. Ao nível quantitativo aplicou-se um questionário, validado por um painel de especialistas na área, composto por questões fechadas, semifechadas e abertas, com uso de uma escala de Likert, administrado a uma amostra de 99 alunos $(n=99)$ com idades entre 14 e 18 anos, sendo 48 do sexo feminino e 51 do sexo masculino.

A segunda fase de recolha de dados, que decorreu em julho de 2017, inclui uma amostra de conveniência constituída por 60 alunos $(n=60), 48$ do género feminino e 12 do género masculino, dos $9^{\circ}, 10^{\circ}, 11^{\circ}$ e $12^{\circ}$ anos de escolaridade de várias regiões do país, num contexto de ensino não-formal, com idades compreendidas entre os 14 e 17 anos. Quanto ao método de investigação, recorreu-se à administração de questionários de resposta fechada.

Os instrumentos de recolha de dados empregados visavam o levantamento de informações relacionadas com a perceção, na primeira pessoa, do modo de aprendizagem de cada um, das suas aspirações, das suas necessidades, da sua relação com Escola e o seu tempo para aprender Ciências. 


\section{Resultados}

Para melhor compreensão e interpretação dos resultados, os mesmos encontram-se representados nos seguintes gráficos, divididos em amostra 1 e amostra 2 que correspondem, respetivamente, à $1^{\mathrm{a}}$ fase e $2^{\mathrm{a}}$ fase da recolha de dados. Os questionários utilizados apresentavam algumas questões iguais, que se encontram tratadas nas figuras 1, 2 e 3.

Quando questionados sobre qual a disciplina de Ciências que mais gostavam, os inquiridos da amostra 1 selecionaram a Matemática, seguida de Biologia, enquanto que a amostra 2 selecionou a Biologia, seguida da Química, Matemática e Física (fig.1).

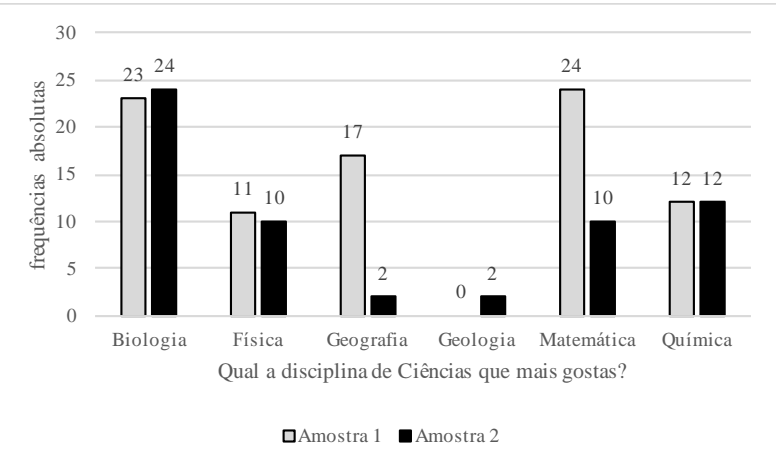

Figura 1. Frequências absolutas das respostas inquiridos (amostra 1 e 2) no que se refere à disciplina de Ciências que mais gostam.

Quando questionados qual a disciplina de Ciências que menos gostavam, os inquiridos da amostra 1 selecionaram a Matemática e Biologia, enquanto que a amostra 2 selecionou a Geografia, seguida de Matemática (fig.2). O que nos leva a perguntar: Por que é que a Matemática é uma das Ciências mais "amada" e, ao mesmo tempo, mais "detestada"? Porquê este extremado "gosto e desgosto" em torno da Matemática?

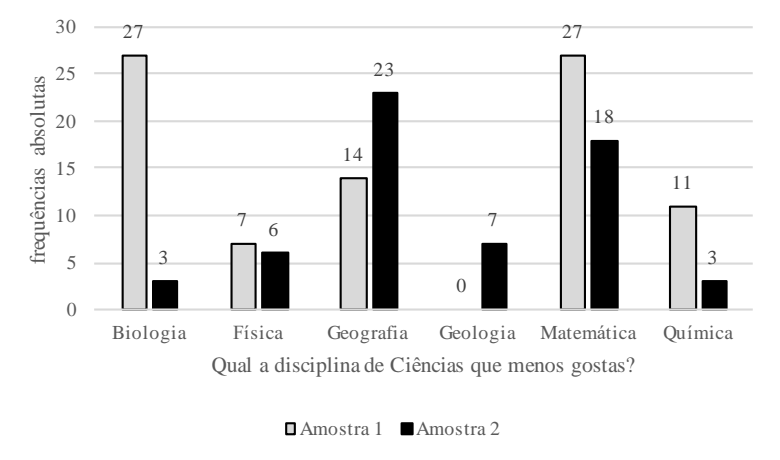

Figura 2. Frequências absolutas das respostas inquiridos (amostra 1 e 2) no que se refere à disciplina de Ciências que menos gostam.

$\mathrm{Na}$ amostra 1, é percetível uma clara simetria entre o número de alunos que manifesta gosto pelas disciplinas questionadas e o número de alunos que as elenca como as que menos gosta, que não é apoiada pelos resultados da amostra 2. Esta última é composta por alunos que frequentaram um curso de verão na área das Ciências, por vontade própria, demostrando, assim, uma afinidade intrínseca nestas áreas, o que por si só poderá justificar uma resposta diferente à registada na primeira fase de inquérito.

Quando inquiridos sobre a importância de aprender Ciências, a maioria dos inquiridos das duas amostras respondeu afirmativamente (fig.3).

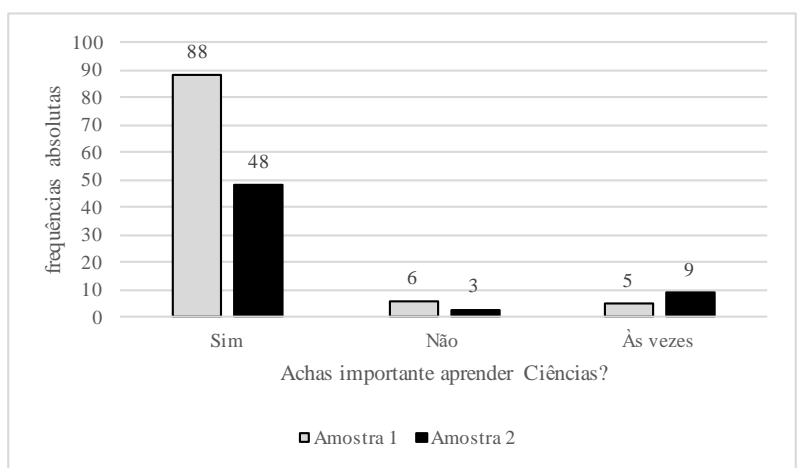

Figura 3. Frequências absolutas das respostas inquiridos (amostra 1 e 2) no que se refere à importância de aprender Ciências.

As figuras 4, 5 e 6 apresentam os resultados das questões do questionário aplicado apenas à amostra 2 . Em relação às suas aspirações, $62 \%$ dos inquiridos da amostra 2 admitem a possibilidade de enveredar por uma carreira científica (fig.4).

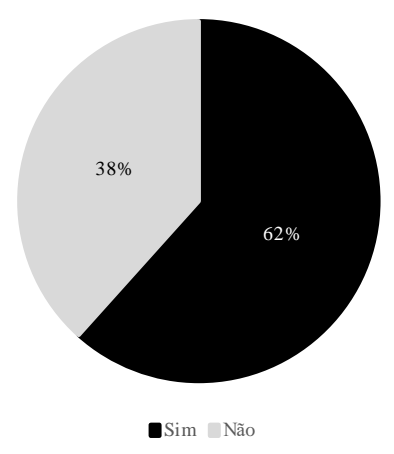

Figura 4. Percentagens das respostas dos inquiridos da amostra 2 quando questionados se pensam enveredar por uma carreira científica.

Por outro lado, os estudantes revelaram opiniões distintas quando interrogados sobre a adequação do modo atual de ensino das Ciências com aquilo que desejam aprender, tendo $53 \%$ dos jovens mostrado a sua insatisfação neste ponto (fig.5), como um dos jovens defende em entrevista de grupo: "Aprender de uma forma diferente deu-lhe uma forma de ver os desafios em Matemática e Ciências de uma forma que fica dentro de Nós" (Fonseca, Cortizo, \& Ferreira, 2016, p.105). 


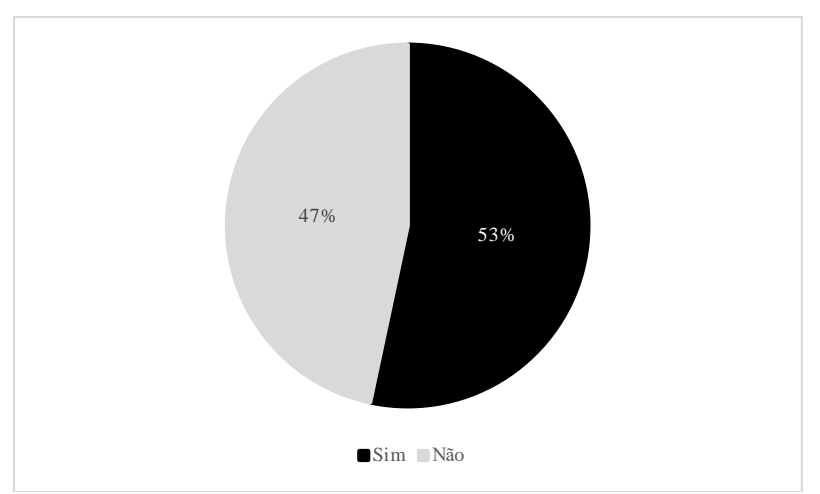

Figura 5. Percentagens das respostas dos inquiridos da amostra 2 quando questionado se o modo atual de ensino das Ciências corresponde àquilo que desejam aprender.

Em consequência, também, grande parte dos estudantes revelaram que o seu ritmo de aprendizagem das Ciências não é respeitado na Escola (57\%), como confidenciado por um dos jovens: "aqui [durante uma das dinâmicas do 100CECCA] nós temos tempo, na sala de aula é tudo muito rápido, e a gente não percebe..." (Fonseca, Cortizo, \& Ferreira, 2016, p.105).

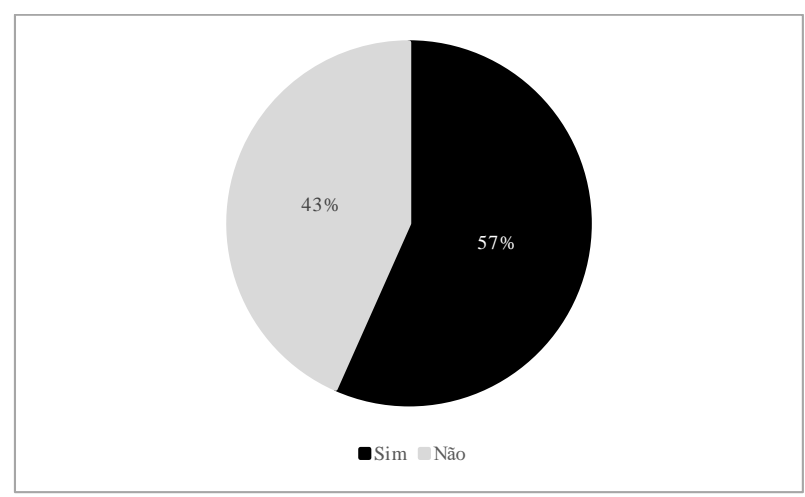

Figura 6. Percentagens das respostas dos inquiridos da amostra 2 quando questionado se o seu ritmo de aprendizagem das Ciências é respeitado na Escola.

\section{Conclusões}

Esta investigação-intervenção exploratória permite-nos reafirmar a importância de um (re)pensar criticamente o Ensino das Ciências. Através da análise dos resultados é evidente a existência de um desprazer ou um (des)gosto dos jovens na sua relação com a Ciência na Escola, apesar de reconhecerem a sua importância.

A diferenciação de resultados entre as duas fases de inquérito é um indicador de que os jovens manifestam um olhar difuso sobre o gosto e a importância destas disciplinas no seu percurso académico e pessoal. Essa diferença suscita a continuação deste trabalho centrado nos argumentos e na autonomia dos jovens alunos, mas de um modo mais aprofundado, quer a nível concetual, epistemológico e formal, a partir dos dados apresentados. Por outro lado, poderá justificar-se o esboço de novas linhas de investigação dirigidas a novos alunos, de ciclos escolares subsequentes.

O (re)pensar o aprender Ciências, passa por identificar, com os alunos, nos diferentes contextos de ensino e aprendizagem, as dúvidas, as inquietudes e expetativas da sua relação interativa com as Ciências, desenvolvendo mutuamente (alunos, professores e outros intervenientes educativos) novas formas de inclusão da Ciência.

A forma transmissiva e recursiva de ensinar Ciência, aliada ao desfasamento entre o ritmo "encomendado" pela tutela e o ritmo dos estudantes, tem de ser alvo de atenção e mudança, evitando a "crise da educação científica" (Cachapuz, Praia \& Jorge, 2004). Esta transformação passa, também, por (re)pensar a relação educativa dentro e fora da Escola e o papel dos seus mediadores.

O tempo da Ciência não é o mesmo tempo da Ciência na Escola. O tempo do(a) professor(a) não é mesmo tempo do(a) estudante. Ao invés de acentuar estas discrepâncias e desencontros, devemos, sim, criar pontes, autonomias e convergências de um tempo profícuo para a Ciência na vida dos jovens, ousando a democratização da literacia científica. Se durante anos a democratização da Educação foi, e ainda é, palavra de ordem, hoje é indispensável unir os jovens à Ciência, formando uma sociedade mais plena de conhecimento, confiando-lhes autoria científica.

\section{Referências}

Baptista, M. (2010). Concepção e implementação de actividades de investigação: um estudo com professores de física e química do ensino básico. (PhD), Universidade de Lisboa, Lisboa. http://hdl.handle.net/10451/1854

Cachapuz, A., Praia, J., \& Jorge, M. (2004). Da Educação em Ciência às Orientações para o Ensino das Ciências: um Repensar Epistemológico. Ciência \& Educação, 10(3), 363-381.

Ferreira, E., Fonseca, M., \& Teixeira, A. (2015). O "voo da mosca" - saberes em ciências: os argumentos dos jovens estudantes e a aprendizagem nos quotidianos educativos. Lumen, 24(2), 55-69.

Fonseca, M., Cortizo, T., \& Ferreira, E. (2016). Como aprendem os jovens ciências? O projeto 100 CECCA. In Tamara Ramiro-Sánchez \& $\mathrm{M}^{\mathrm{a}}$ Teresa Ramiro (Ed.), Avances en Ciencias de la Educación y del Desarrollo (pp. 101-106). Granada: Asociación Española de Psicología Conductual (AEPC).

Gay, L. R., Mills, G. E., \& Airasian, P. W. (2011). Educational research: Competencies for analysis and applications (10 ed.): Pearson Higher Education.

Martins, J., Ribeiro, T., Fonseca, M., Cortizo, T., Sousa, A., Lima, F., \& Ferreira, E. (2017). 100cecca: Knowing, Studying And Cooperating In Science To Learn. 5th International Congress of Educational Sciences and Development., Santander, España.

Matos, M. (2017). O Tempo na escola. A Página da Educação, 2(209), 24-25.

Moreira, M. A. (2002). A Teoria dos Campos Conceituais de Vergnaud, o Ensino de Ciências e a pesquisa nesta área. Investigações em ensino de ciências. Porto Alegre, 7(1), 7-29.

Nóvoa, A., \& Bandeira, F. (2005). Evidentemente: histórias da educação. 
Perrenoud, P. (2001). Ensinar: agir na urgência, decidir na incerteza ( 2 ed.). Porto Alegre: Artmed.

Vasconcelos, C., \& Almeida, A. (2012). Aprendizagem Baseada na Resolução de Problemas no Ensino das Ciências: Propostas de trabalho para Ciências Naturais, Biologia e Geologia (Vol. 13). Porto: Porto Editora.

Vergnaud, G. (2000). Teoria dos Campos Conceituais. I Seminário Internacional de Educação Matemática. São Paulo: SBEM, 1. 